\section{Processos da construção da Política Nacional de Promoção da Saúde}

\author{
Processes in the construction of the Brazilian \\ National Health Promotion Policy
} Procesos de construcción de la Política Nacional
de Promoción de la Salud

\author{
${ }_{1}^{1}$ Pontifícia Universidade \\ Católica de Minas Gerais, \\ Belo Horizonte, Brasil. \\ 2 Centro Universitário de Sete \\ Lagoas, Sete Lagoas, Brasil. \\ Correspondência \\ J. L. Ferreira Neto \\ Pontifícia Universidade \\ Católica de Minas Gerais. \\ Av. Itaú 525, Belo Horizonte, \\ MG 30535-012, Brasil. \\ jleite.bhe@terra.com.br
}

\begin{abstract}
We investigated the processes involved in the construction of the Brazilian National Health Promotion Policy (PNPS) through the analysis of three documents produced by the Ministry of Health from 2002 to 2005 and the final text of the National Health Promotion Policy, approved in 2006. We interviewed five subjects who participated in drafting the PNPS, three of whom were Ministry of Health administrators, plus two researchers. The documents were explored with discourse analysis. The article contributes to the debate on the development of the PNPS. Health promotion showed various points of disagreement, which led to the delay in the document's final approval. International induction via funding proved to be a crucial element for defining the final wording of the PNPS, reestablishing the emphasis (subject to criticism) on lifestyle changes in its "Actions". The article highlights the negotiated consensus that led to the creation of the PNPS Management Committee, with participation by various sub-sectors, an innovative structure within the Ministry of Health.
\end{abstract}

Health Promotion; Health Policy; Unified Health System; Government Publications
João Leite Ferreira Neto 1

Luciana Kind 1

Maria Carolina Costa Resende 2

Natália Silva Colen 1

\section{Resumo}

Investigou-se os processos de construção da Política Nacional de Promoção da Saúde (PNPS), pela análise de três documentos produzidos pelo Ministério da Saúde entre 2002 e 2005 e do texto final da PNPS. Foram entrevistados cinco sujeitos que participaram da construção da PNPS, dos quais três eram gestores do Ministério da Saúde e dois pesquisadores. Os documentos foram explorados com a Análise do Discurso. O artigo contribui para aprofundar os debates sobre o processo de construção da PNPS. A promoção da saúde revelou seus antagonismos, o que motivou a demora de sua aprovação final. A indução internacional via financiamento demonstrou ser o elemento crucial para a definição da forma final da PNPS, trazendo de volta a criticada ênfase na mudança de estilos de vida em suas "Ações". Destaca-se o processo de produção negociada de consenso, que culminou com a criação do Comitê Gestor da PNPS, com a participação de diversos subsetores, estrutura inovadora no Ministério da Saúde.

Promoção da Saúde; Política de Saúde; Sistema Único de Saúde; Publicações Governamentais 
"O discurso não é simplesmente aquilo que traduz as lutas ou sistemas de dominação, mas aquilo por que, pelo que se luta, o poder do qual queremos nos apoderar" 1 (p. 10).

O objetivo deste artigo é investigar os processos envolvidos na construção da Política Nacional de Promoção da Saúde (PNPS). Adotamos a definição proposta por Schlager 2 (p. 293) "o termo processo conota temporalidade, um desdobramento de ações, eventos e decisões, que podem culminar numa decisão de autoridade, a qual, ao menos temporariamente, associa tudo isso dentro da jurisdição do aparato governamental". Na análise desses processos, interessa-nos entender os meandros do debate empreendido na composição da Política Nacional de Promoção da Saúde, as tendências teórico-políticas, as relações de poder que os permeiam, e os fatores determinantes que corroboraram para o estabelecimento do desenho final da PNPS.

Enquanto a literatura sobre promoção da saúde é abundante, a abordagem da história da construção da PNPS para o período por nós investigado possui poucas publicações 3,4,5. Destaca-se a coletânea organizada por gestores do Ministério da Saúde, que teve como autores pessoas que compuseram o processo de elaboração da PNPS 6. Em suas linhas e entrelinhas são expostas "alguns dos saberes e forças que fizeram emergir o texto da Política que foi aprovado e não outro" 6 (p. 15).

Promoção da saúde, como noção genérica, goza de um prestígio quase consensual. Entretanto, quando adentra formalmente no campo das políticas públicas em 1974, por meio do Relatório Lalonde 7, rapidamente se torna foco de debates acalorados. A literatura sobre o assunto se divide entre acusá-la de atender à tendência neoliberal de responsabilizar/culpabilizar os indivíduos pela própria condição de saúde, isentando o Estado de parte de suas funções, ou apoiá-la por sua definição positiva de saúde e por suas diretrizes para o desenvolvimento de práticas intersetoriais e participativas na gestão dos problemas de saúde. Esse debate escapa ao foco deste estudo, mas é contemplado por alguns autores 8,9,10.

A política de promoção da saúde teve uma trajetória fortemente conflituosa, estendendo-se por oito anos desde a sua entrada em pauta até a sua formulação final, passando por duas diferentes gestões federais.

Apesar de preconizada no princípio constitucional da integralidade, a promoção da saúde adentra na agenda do Ministério da Saúde apenas em 1998, durante a gestão ministerial do Partido da Social Democracia Brasileira (PSDB), por meio do projeto Promoção da Saúde: um Novo Modelo de Atenção, em cooperação com o Programa das Nações Unidas para o Desenvolvimento (PNUD), sob a responsabilidade da Secretaria de Políticas de Saúde, Ministério da Saúde 3,4. O debate se intensificou em 2003, no início da gestão do Partido dos Trabalhadores (PT) à frente da pasta da saúde, com a definida intenção de construir uma política nacional em bases diversas do que vinha sendo realizado até então. Apesar disso, a PNPS só foi estabelecida em 2006, como consequência de um longo e tortuoso debate, nem sempre diretamente travado. Portanto, também no plano nacional os aspectos de dissensão em torno da promoção reaparecem, ainda que com inflexões peculiares que analisaremos mais adiante.

Anteriormente ao período estudado, houve várias discussões que formalizaram insatisfações a respeito do foco biomédico e defendiam novos modelos de atenção e propostas de promoção da saúde, com destaque para o I Congresso de Secretários Municipais de Saúde das Américas, em Fortaleza (Ceará) no ano de 1995 11, e as ações da Vigilância da Saúde no Ministério da Saúde, que já avançavam na tentativa de superação da dicotomia entre práticas coletivas e práticas individuais 12

A aprovação da PNPS se deu mediante portaria ministerial assinada pelo então ministro Saraiva Felipe, em 30 de março de 2006. Esse instrumento legal revela que boa parte das políticas de saúde tem sua vigência voltada para o interior do setor público. Mesmo contando com um representante da Agência Nacional de Saúde Suplementar (ANS), o foco da PNPS são os níveis federal, estadual e municipal da saúde, ainda que algumas das Ações nela designadas visem a atingir setores não governamentais. Ressaltamos o escopo da noção de política aqui colocada. Se nos estudos de política pública parte-se, em geral, de um conjunto ampliado de grupos de interesses envolvidos, seja de agências governamentais, do legislativo, da opinião pública, da academia, da mídia, entre outros 13, temos na construção da PNPS um conjunto bem mais reduzido.

\section{Método}

Este estudo tem como procedimentos metodológicos uma análise documental e entrevistas com cinco sujeitos que participaram da construção da PNPS, sendo três deles gestores do Ministério da Saúde e os outros dois pesquisadores. O critério de inclusão foi o envolvimento nos debates das negociações que antecederam a composição final da PNPS, entre 2003 e 2006. Os gestores entrevistados ocuparam cargo de direção ou de coordenação durante o processo de formulação da 
PNPS. Trabalhamos, portanto, com uma amostra intencional, visando a localizar informantes que tivessem um papel significativo, e com o propósito de recolher informações complementares à análise documental. Entendíamos que escutar alguns participantes-chave desse processo poderia nos dar outras perspectivas para a análise documental, uma vez que a literatura encontrada sobre o histórico da PNPS era reduzida e os documentos em geral não trazem aos pesquisadores precisões suplementares necessárias a uma análise mais acurada. Optamos por centrar nossa pesquisa nos documentos sem fazer um uso exaustivo das entrevistas, ainda que a transcrição e análise das mesmas em muito auxiliaram a leitura dos documentos e a formulação de hipóteses analíticas. Privilegiamos também a literatura que discute a Política, grande parte dela escrita por sujeitos que participaram de sua elaboração, recorrendo às entrevistas quando as informações publicadas não eram suficientes ou trouxessem novidades que não estivessem em materiais já publicados.

A combinação entre documentos e entrevistas permitiu o aprofundamento da análise, fornecendo-nos elementos sobre contexto, autoria e confiabilidade dos textos 14 . Celard 14 (p. 296) sugere que o pesquisador que faz uso de documentos deve "localizar os textos pertinentes e avaliar sua credibilidade, assim como, a sua representatividade". Selecionamos quatro documentos centrais nesse processo, dois deles por serem esboços preliminares da Política, outro por representar uma passagem entre ambas as gestões e o texto final da PNPS. Inicialmente desenvolvemos uma análise comparativa entre dois documentos produzidos pelas duas gestões com o intuito de subsidiar a formulação da PNPS. O primeiro documento (D1: Ministério da Saúde. Política Nacional de Promoção da Saúde. Documento para discussão; 2002) 15, foi elaborado no final da gestão do PSDB, após a cooperação do Ministério da Saúde com o PNUD. O segundo (D2: Ministério da Saúde. Promoção da Saúde, Um Novo Modelo de Atenção. Proposta de revisão substitutiva; 2003), funciona como transição entre os dois governos. Trata-se do relatório do trabalho de cooperação com o PNUD ocorrido na gestão do PSDB, mas escrito no governo seguinte com um tom de clara ruptura em relação à anterior. O terceiro documento (D3: Ministério da Saúde. Política Nacional de Promoção da Saúde. Documento preliminar para discussão; 2005), elaborado na gestão do PT, possuía o mesmo objetivo do primeiro e com título e subtítulo similares: Política Nacional de Promoção da Saúde: documento preliminar para discussão. Finalmente, trabalhamos o texto definitivo da PNPS (D4: Mi- nistério da Saúde. Política Nacional de Promoção da Saúde; 2006).

$\mathrm{Na}$ análise documental utilizamos os instrumentos de análise do discurso com base em Fairclough 16. Essa combinação permitiu aprofundar elementos sobre a natureza e a lógica dos textos em análise, os sentidos de seus conteúdos, o contexto de produção e suas práticas de composição. Em concordância com Fairclough 16, considerouse o discurso como uma prática social que não somente representa o mundo, mas o constitui, mediante a construção de significados. O processo de construção de significados e de realidades numa política pública, em geral, acarreta embates e processos de negociação.

Fairclough 16 nos sugere uma análise que contemple a dimensão tridimensional do discurso, envolvendo a análise do texto em si; a análise das práticas discursivas focalizando sua produção, distribuição e consumo; e a análise da prática social da qual o discurso é parte, neste caso a formulação de políticas governamentais de saúde. Essas dimensões se encontram inevitavelmente superpostas. Buscamos transitar sobre esses diversos níveis privilegiando no nível do texto seu vocabulário, sua gramática e estrutura, assinalando seus elementos de coesão e ruptura. No nível da prática discursiva abordamos sua intertextualidade, como é atravessado por outros textos; seu contexto de produção, lugar político de enunciação, interesses, forças que o compõem, e a que se destina. No nível da prática social buscamos explicitar as circunstâncias políticas e institucionais de sua enunciação.

As diferentes modalidades de análise do discurso têm em comum trabalharem com base em uma dupla articulação. Por um lado carregam a concepção de que o discurso envolve ações de sujeitos situados em contextos particulares e trabalham a articulação da linguagem elementos de ordem não linguística (dimensões políticas, históricas, institucionais, ideológicas, entre outras). Por outro, as diferentes análises do discurso desenvolvem análises respeitando as articulações próprias da estrutura do texto, em vez de transformar seus temas em categorias abstraídas de seu contexto enunciativo. Assim, evita-se que a análise dos temas se descole da análise das articulações propriamente textuais e linguísticas. A análise das modalidades de enunciação dos textos de uma política pode revelar concepções e perspectivas que vão além dos temas que as mesmas abordam.

A pesquisa foi aprovada pelo Comitê de Ética em Pesquisa da Secretaria Municipal de Saúde de Belo Horizonte, Minas Gerais, Brasil (parecer no 00690410213-09A) e cumpriu as normas éticas vigentes. 


\section{Resultados}

\section{Análise dos documentos preliminares}

Focalizamos nesta subseção a comparação entre os "documentos preliminares para discussão" produzidos por cada gestão (D1 e D3), utilizando como mediação o relatório do PNUD operacionalizado entre 1999 e 2002, mas escrito na gestão seguinte em 2003 (D2). Finalmente analisamos o texto final da PNPS (D4). Uma síntese desses documentos pode ser visualizada na Tabela 1.

Os documentos analisados revelam um embate entre dois diferentes grupos associados a partidos políticos que se alternaram no poder. Concomitantemente, há variados micro enfrentamentos ligados a elementos históricos, institucionais, de filiação teórico-ideológica, alguns dos quais compõem nossa análise.

Em função do desenho da pesquisa obtivemos poucas informações relativas ao período anterior a 2003. A literatura aponta que apesar de haver uma intenção em elaborar-se uma política de promoção na gestão do PSDB, isto não se mostrou factível. Atribui-se esse insucesso a uma série de dificuldades de consenso e de articulação ${ }^{2}$. No início da gestão de 2003, decidiu-se pela retomada do debate sobre a promoção da saúde em agosto, a cargo da Secretaria Executiva do Ministério da Saúde, pelo entendimento de que essa PNPS deveria manter forte articulação com o conjunto das ações de saúde. Havia um Grupo Redator formado por representantes do Ministério da Saúde, da Organização Pan-Americana da Saúde (OPAS), do Conselho Nacional de Secretários Municipais de Saúde (CONASEMS) e de gestores municipais, visando a uma composição plural que atendesse a uma lógica mais transversal das ações de promoção. No final de 2004, devido a mudanças no Ministério da Saúde, a elaboração da PNPS ficou a cargo da Coordenação de Doenças e Agravos não Transmissíveis (CGDANT), na Secretaria de Vigilância em Saúde, o que provocou divergências. Um dos gestores entrevistados discordou frontalmente da decisão, também contestada na literatura, que associa a isso "uma visão reducionista que a mantinha restrita ao âmbito da prevenção de riscos ou doenças" 3 (p. 2307). Em 2005, foi instituído o Conselho Gestor da PNPS ampliando o número de participantes e o envolvimento de mais representantes de áreas técnicas governamentais. Em contrapartida, um gestor entrevistado sugere que com essa mudança a PNPS ganhou em capacidade operacional por ter saído de uma secretaria meio para uma secretaria fim. De qualquer modo as várias mudanças ocorridas no Ministério da Saúde exigiram várias rodadas de discus- sões e várias revisões do texto da PNPS, sendo um dos fatores para a demora da aprovação final da Política. Houve ainda uma tentativa, na gestão do Ministro José Gomes Temporão, de criação de uma Secretaria de Atenção Básica e Promoção, mas nada aconteceu. Na Tabela 2 , pode-se visualizar essa linha do tempo.

Historicamente, a circunstância político-institucional chave para o desencadeamento da construção de uma política de promoção foi a indução, por meio de financiamento, de organismos internacionais para inseri-la na agenda brasileira. Destacamos aqui três momentos, sendo o primeiro deles nos antecedentes da incorporação do debate no Ministério da Saúde. Segundo Rocha 17, na década de 1990 a OPAS tomou a promoção da saúde como estratégia central no Brasil. Uma de suas estratégias foi a contratação de consultores que assumiam "formalmente o compromisso de implantar, coordenar ou colaborar em grupos de trabalho, na área de promoção da saúde do país" 17 (p. 42). O segundo momento, já mencionado, foi a institucionalização do tema no Ministério da Saúde do Projeto no 98/006, financiado pelo PNUD, cujo objetivo era viabilizar a transformação do modelo de atenção pelo eixo da promoção da saúde. Essas ações de cooperação internacional se mantiveram como uma força permanente cuja presença influenciará inclusive o desenho final da PNPS. O terceiro momento foi a "estratégia global para alimentação, atividade física e saúde”, elaborada pela Organização Mundial da Saúde (OMS) em 2004, e que definiu as primeiras ações da PNPS, que iniciaram em 2005, mesmo antes da aprovação do texto final 4,5 .

A influência internacional na PNPS brasileira foi um dos elementos centrais da crítica feita pela gestão de 2003 ao primeiro documento para discussão da PNPS. O objetivo central do relatório sobre o Projeto no 98/006 era promover revisões substantivas "devido às modificações ocorridas no Brasil quanto aos compromissos sociais do novo Governo e a composição de uma nova equipe de gestão do projeto", além de solicitar o adiamento de seu prazo de vigência (D3, p. 18). A ideia base era que a nova gestão deveria rever as discussões "fazendo-as convergir com os debates acerca do SUS e sintonizando-as à singularidade da realidade brasileira" (D3, p. 18).

Esse tom permaneceu durante o processo, reaparecendo de forma mais aberta no livro publicado após a aprovação da PNPS 6. No prefácio, escrito pelo Secretário Executivo do período 2003-2004, encontramos dois argumentos centrais dessa crítica. O primeiro é o equívoco de centrar as ações de promoção sobre o estilo de vida, favorecendo o retraimento das respon- 


\begin{tabular}{|c|c|c|c|}
\hline Documento & Objetivos & $\begin{array}{l}\text { Estrutura do texto e síntese das } \\
\text { proposições }\end{array}$ & Dados sobre autoria \\
\hline $\begin{array}{l}\text { D1: Política Nacional } \\
\text { de Promoção da Saúde } \\
\text { (documento para } \\
\text { discussão) } 15\end{array}$ & $\begin{array}{l}\text { Atuar para que as condições ambientais em } \\
\text { geral e de conduta sejam favoráveis à saúde } \\
\text { dos indivíduos e comunidades; contribuir } \\
\text { para reduzir as desigualdades sociais; } \\
\text { qualificar o SUS na perspectiva da } \\
\text { promoção da saúde }\end{array}$ & $\begin{array}{l}\text { Justificativa para se promover a saúde } \\
\text { Estratégias e linhas de ações } \\
\text { Inquérito com gestores } \\
\text { Propostas para discussão } \\
\text { Referências (4 documentos governamentais, } \\
6 \text { referências de literatura internacional, } 3 \\
\text { referências de literatura nacional e } 6 \text { livros } \\
\text { de intelectuais brasileiros e estrangeiros) }\end{array}$ & $\begin{array}{l}\text { Apresentação pelo } \\
\text { Secretário de Políticas } \\
\text { de Saúde }\end{array}$ \\
\hline $\begin{array}{l}\text { D2: Promoção da Saúde, um } \\
\text { novo modelo de atenção. } \\
\text { Proposta de Revisão } \\
\text { Substitutiva - Projeto no } \\
98 / 0069\end{array}$ & $\begin{array}{c}\text { Visa a mudanças substantivas na proposta } \\
\text { do governo anterior e extensão das } \\
\text { ações até } 2005\end{array}$ & $\begin{array}{l}\text { Relatório de revisão do projeto 98/006, } \\
\text { "Promoção da saúde: um novo modelo } \\
\qquad \text { de atenção" } \\
\text { Formato de projeto, incluindo resultados } \\
\text { esperados, orçamento, etc. }\end{array}$ & $\begin{array}{c}\text { Não tem apresentação ou } \\
\text { dados de autoria }\end{array}$ \\
\hline $\begin{array}{l}\text { D3: Política Nacional } \\
\text { de Promoção da Saúde } \\
\text { (documento preliminar para } \\
\text { discussão) }\end{array}$ & $\begin{array}{l}\text { Apresenta } 6 \text { objetivos: estimular políticas e } \\
\text { ações intersetoriais; definir instrumentos de } \\
\text { avaliação; fomentar pesquisas; sensibilizar e } \\
\text { qualificar gestores, trabalhadores e usuários; } \\
\text { favorecer a preservação e promoção do } \\
\text { meio ambiente; superar a fragmentação } \\
\text { das ações mediante o fortalecimento } \\
\text { da promoção como eixo articulado dos } \\
\text { serviços e de políticas }\end{array}$ & $\begin{array}{l}\text { Possui } 4 \text { seções: marco teórico-político, } \\
\text { propósito, diretrizes e agenda de ações } \\
\qquad \text { associadas aos objetivos. } \\
\text { Referências (8 documentos governamentais } \\
\text { e } 2 \text { documentos da OMS, } 5 \text { referências de } \\
\text { literatura nacional e nenhuma de literatura } \\
\text { internacional) }\end{array}$ & $\begin{array}{l}\text { Apresentação pelo } \\
\text { Secretário de Vigilância } \\
\text { em Saúde e pelo Ministro } \\
\text { da Saúde } \\
\text { É assinado por redatores e } \\
\text { colaboradores }\end{array}$ \\
\hline $\begin{array}{l}\text { D4: Política Nacional de } \\
\text { Promoção da Saúde }\end{array}$ & $\begin{array}{l}\text { Objetivo geral: promover a qualidade de } \\
\text { vida e reduzir vulnerabilidade e riscos à } \\
\text { saúde relacionados aos seus determinantes } \\
\text { e condicionantes; desdobrado em } 12 \\
\text { objetivos específicos }\end{array}$ & $\begin{array}{l}\text { Possui uma longa introdução, similar } \\
\text { ao marco teórico-político de D3; } \\
\text { objetivos, estratégias; delimitação das } \\
\text { responsabilidades nas três esferas de } \\
\text { gestão; e as ações específicas } \\
\text { Referências (7 documentos governamentais) }\end{array}$ & $\begin{array}{l}\text { Apresentação pelo } \\
\text { Ministério da Saúde } \\
\text { e autoria de uma } \\
\text { comissão composta } \\
\text { por } 10 \text { representantes } \\
\text { institucionais }\end{array}$ \\
\hline
\end{tabular}

OMS: Organização Mundial da Saúde; SUS: Sistema Único de Saúde.

Fonte: dados da pesquisa.

sabilidades do Estado. Para se contrapor a esse equívoco, fala-se em duas direções da promoção. Uma delas "normatiza estilos de vida e culpa o indivíduo" 18 (p. 11), vista como tendência internacional de redução dos compromissos do Estado. Suas estratégias privilegiam o enfoque na nocividade de hábitos ligados ao tabaco, à ausência de atividade física e à alimentação. A segunda direção vincula a promoção "à autonomia de sujeitos e coletividades no seu modo de viver" 18 (p. 11), uma promoção antropofágica, à brasilei- ra, na defesa do SUS. O que vemos nos debates é a caracterização de duas concepções em combate. A primeira, que produziu o D1 e o projeto agora criticado, teria suas raízes no movimento internacional de promoção da saúde, enquanto a segunda teria suas bases teórico-políticas na reforma sanitária brasileira.

O segundo argumento da discordância, associado ao primeiro, que encontramos em D2, D3 e no livro, adverte contra o risco de transformarem a promoção em paradigma, dissociando-a da 
Linha do tempo da construção da Política Nacional de Promoção da Saúde (PNPS).

\begin{tabular}{|c|c|c|c|}
\hline Período & Principais eventos & Documentos & Bibliografia \\
\hline Antecedentes: 1986-1997 & $\begin{array}{l}\text { 8ạ CNS; } \\
\text { la Conferência Internacional de Promoção } \\
\text { da Saúde }\end{array}$ & $\begin{array}{l}\text { Relatório da 8ạ CNS (1986), } \\
\text { Carta de Ottawa (1986) }\end{array}$ & Rocha 17 \\
\hline Gestão PSDB: 1998-2002 & $\begin{array}{c}\text { Projeto no 98/006: Promoção da Saúde: um } \\
\text { Novo Modelo de Atenção, cooperação com } \\
\text { o PNUD; ações diversas visando à inserção } \\
\text { do debate no país; publicação do periódico } \\
\text { Promoção } \\
\text { da Saúde }\end{array}$ & $\begin{array}{l}\text { Ministério da Saúde, } \\
2002 \text { (D1) }\end{array}$ & Castro 3 , Buss \& Carvalho 4 \\
\hline $\begin{array}{l}\text { Gestão PT 2003-2004: } \\
\text { Secretaria Executiva, Ministério } \\
\text { da Sáude 2003-2004 }\end{array}$ & $\begin{array}{l}\text { Eventos e mapeamento de experiências; duas } \\
\text { oficinas de trabalho; constituição do Grupo } \\
\text { Redator da Política; Estratégia Global para } \\
\text { alimentação, atividade física e saúde da } \\
\text { OMS (2004). }\end{array}$ & $\begin{array}{l}\text { Ministério da Saúde, } \\
2003 \text { (D2) }\end{array}$ & Castro 3 , Buss \& Carvalho 4 \\
\hline $\begin{array}{l}\text { Gestão PT 2004-2006: } \\
\text { Coordenação de Doenças e }\end{array}$ & $\begin{array}{l}\text { Programa Pratique Saúde; instituição do Comitê } \\
\text { Gestor da Política (2005); formulação da PNPS }\end{array}$ & $\begin{array}{l}\text { Ministério da Saúde, } \\
2005 \text { (D3) }\end{array}$ & $\begin{array}{l}\text { Castro 3, Castro \& Malo 6, Buss } \\
\text { \& Carvalho 4, Malta et al. } 5\end{array}$ \\
\hline $\begin{array}{l}\text { Agravos não Transmissíveis } \\
\text { (CGDANT) da Secretaria de } \\
\text { Vigilância em Saúde, Ministério } \\
\text { da Saúde 2004-2006 }\end{array}$ & & $\begin{array}{l}\text { Ministério da Saúde, } \\
2006 \text { (D4) }\end{array}$ & \\
\hline
\end{tabular}

CNS: Conferência Nacional de Saúde; OMS: Organização Mundial da Saúde; PNUD: Programa das Nações Unidas para o Desenvolvimento; PSDB: Partido da Social Democracia Brasileira; PT: Partido dos Trabalhadores.

Fonte: dados da pesquisa.

clínica. Aposta-se na articulação entre política/ clínica e gestão/atenção. Principalmente enfatiza-se que a promoção da saúde deve ser tomada no arcabouço mais amplo da produção da saúde, da qual ela é um componente importante, mas não é seu eixo central. Essa é uma categoria marxista, associada à noção ampliada de saúde estabelecida na 8a Conferência Nacional de Saúde (CNS). No D2, uma das justificativas de revisão do projeto deve-se à constatação de que "ganhou destaque a execução de programas e projetos que intervieram mais nos campos de estilos de vida. hábitos saudáveis, capacitação e divulgação de informação" (D2, p. 11).

Há ainda no D2 uma crítica à estratégia metodológica do projeto BRA: a educação em saúde não deve ser desenvolvida com base em "programas e cursos pensados verticalmente", mas seus temas formulados "conforme as questões que se apresentem no cotidiano dos serviços” (D2, p. 13). A dimensão democrática e participativa visando à autonomia dos indivíduos e coletivos é uma ên- fase que acompanha os três últimos documentos e não está presente no primeiro.

Não tivemos acesso nesta pesquisa à reação dos partidários da primeira concepção, uma vez que tudo o que se seguiu até a aprovação final da Política foi produzido por influência majoritária dos que esposavam a segunda concepção. Portanto, como ocorre em todo debate, talvez tenhamos uma imagem um pouco caricatural da primeira concepção, uma vez que à exceção do D1, os demais documentos são da gestão posterior. Isso é um elemento de ponderação importante na combinação de análises aqui realizada. Em nosso corpus documental temos três textos - D2, D3 e D4 - que têm como pano de fundo a crítica a um outro, o D1, e a seu projeto, ao passo que este não possui réplica na série com a qual trabalhamos.

Uma comparação inicial entre os dois "documentos para discussão", o de 2002 (D1) e o de 2005 (D3), pode gerar diferentes impressões. Do ponto de vista temático percebemos similari- 
dades. D1 critica o modelo de atenção vigente, contestando o seu caráter biomédico, focado na atenção individual. Em consonância, o D3 fala da incapacidade do modelo biomédico modificar os determinantes sociais por estar centrado na atenção aos sintomas (D3, p. 6), além de denunciar o alto custo desse modelo. Ambos, D1 e D3, apontam a fragmentação das ações em saúde e veem a promoção como um caminho para a articulação das agendas dos serviços e a elaboração das políticas. A intersetorialidade é afirmada, em diversos trechos, como eixo fundamental para uma PNPS, visando à maior interação entre os diversos setores, ministérios e atores sociais, com ações na gestão, atuação e políticas. Os exemplos de proximidades poderiam se estender, mas curiosamente, D3 faz uma menção do documento preliminar da gestão anterior apenas na apresentação, mas ele não é utilizado como referência bibliográfica, permanecendo apenas como adversário subentendido em sua defesa das ideias.

Em contrapartida, mediante uma análise do discurso da estrutura dos textos, observa-se marcadas diferenças na presença e, principalmente, na ausência de certos temas e referências e nos modos de enunciação. D3 preocupa-se em inserir a promoção da saúde na trajetória da reforma sanitária, em consonância com o D2. Como indicativo disso, sua primeira referência bibliográfica é o relatório da 8a CNS, em sua afirmação da garantia da saúde como direito de cidadania, tendo em sua base o conceito ampliado de saúde e a necessidade de criar políticas públicas para promovê-la. Já o D1, apesar de reconhecer que a promoção da saúde resgata uma das promessas da reforma sanitária, não menciona a $8^{\mathrm{a}} \mathrm{CNS}$, se alinhando mais diretamente às conferências internacionais. Um elemento que confirma essa interpretação são as seis referências da literatura internacional no D1 contra nenhuma referência presente em D3. No corpo do texto, enquanto D1 multiplica as menções às experiências internacionais de promoção, com destaque para o Canadá, D3 não faz menção a elas. Podemos deduzir que a diferença entre os dois documentos está menos em reconhecer a importância da promoção para o avanço do SUS, mas no movimento marcadamente político de alinhá-lo com o nosso histórico e não com as contribuições do movimento internacional de promoção da saúde como faz o D1.

Dois entrevistados acentuam que o grupo que assumiu a Secretaria Executiva do Ministério da Saúde em 2003 já tinha críticas prévias às discussões sobre a promoção da saúde realizada no Brasil. Mesmo assim, decidiram convocar um coletivo ampliado para debater a PNPS, apon- tando as críticas a certo formato anterior ao debate da promoção. Um forte fator de dissensão foi o enunciado do terceiro objetivo do D1 (p. 28): "Qualificar o SUS na perspectiva da promoção da saúde". Como reage um entrevistado, "a gente não vai aceitar a promoção da saúde estilo de vida e tal, e essa fala de vocês que a promoção da saúde vem pra requalificar o SUS, a gente está fora". Ele lembra que a 8a CNS é anterior à Carta de Ottawa. Essa discordância reverbera no título do livro publicado após a aprovação da PNPS: SUS: Ressignificando a Promoção da Saúde. A ideia de "ressignificar" a promoção sinaliza a intenção de diferenciá-la do movimento internacional e acentuar sua vinculação com a história do SUS, evitando a perspectiva de que seria a promoção que qualificaria o SUS. Entretanto, os organizadores do livro preferem adotar uma postura mais conciliadora ao salientar as proximidades, em vez das diferenças, entre as duas direções da promoção, respeitando a composição plural do grupo de autores, que também participaram da elaboração da PNPS: "SUS e Movimento Internacional de Promoção da Saúde têm princípios sinergéticos" 6 (p. 14).

Um conteúdo que tem forte presença no D1, mas desaparece no D3, são os dados epidemiológicos. Acentua-se que o Brasil vive sua "transição epidemiológica” com a diminuição da mortalidade por doenças infecciosas e o aumento de doenças crônicas não transmissíveis, apresentando estatísticas sociais e epidemiológicas. A importância da epidemiologia não é negada no D3; existem 18 menções a ela, mas não se faz uma discussão de números. Há uma crítica quanto à relevância dos dados epidemiológicos como fundamento para se pensar uma política. Se no documento de 2002 há uma preocupação como "o desafio das evidências na promoção da saúde" (D1, p. 15), o de 2005 aponta o limite destas evidências por estarem ligadas apenas "ao comportamento e aos hábitos de vida dos sujeitos" (D3, p. 13) e, portanto, não seriam base suficiente para a construção de uma PNPS. Há um insistente repúdio à tese de que "a promoção da saúde lida com estilos de vida [...] onde a população perde de vista o que é uma vida saudável" (D3, p. 13). Ao contrário, defendem que os "modos de viver" (ao substituírem a expressão clássica "estilos de vida”, visam a acentuar uma mudança conceitual) "não se referem apenas ao exercício da vontade elou liberdade individual e comunitária [...] mas envolve forças políticas, econômicas, afetivas $e$ sociais" (D3, p. 8).

Outra justificativa da não utilização de dados epidemiológicos no D3 foi enunciada por um gestor ao avaliar o documento de 2002: "ele na verdade é um diagnóstico epidemiológico, uma 
análise de situação de saúde, alguns princípios e depois estudos de caso de coisas que aconteciam, 4 ou 5 estudos de caso de coisas que aconteciam na promoção da saúde no Brasil. E isso não era política. E assim, isso foi um primeiro embate". O grupo que redige o D3 dá uma grande importância ao que consideram o "marco teórico-político". Inclusive o nome dado à Introdução da PNPS por um dos entrevistados é de "parte teórica", escrita pelo grupo redator ainda no período em que a Política permanecia na gestão da Secretaria Executiva do Ministério da Saúde, e pouco modificada posteriormente. Um dos entrevistados critica essa postura: "Eu diria que na Secretaria Executiva faltou operacionalização, embora tivesse uma discussão conceitual rica, mas do ponto de vista de isso se tornar, se materializar em coisas concretas, isso teve algum tipo de lentidão". De qualquer modo, pode-se questionar: por que essa insistência nos aspectos teórico-políticos, por vezes em detrimento dos aspectos operacionais? Qual a razão da luta por manter um discurso com essa orientação?

Essa postura relembra a experiência similar ocorrida durante a Assembleia Nacional Constituinte, quando os reformistas da saúde "apostavam que, compondo um texto constitucional que constasse dos princípios básicos da reforma, o processo estaria garantido" 19 (p. 68). No caso estudado, o grupo da Secretaria Executiva até detalha bastante as ações, mas dentro das direções da agenda internacional criticada pelos mesmos, criando um texto híbrido. Preserva-se a "pureza" dos princípios da "parte teórica”, como se a dimensão ideológica fosse mais central do que a operacional.

No plano da organização gramatical de como a promoção da saúde é enunciada, temos uma marcada diferença. No D1 a promoção da saúde é apresentada como uma totalidade homogênea e bem definida, ocupando a função de sujeito em diversas frases: "A promoção da saúde leva a refletir sobre o objeto saúde [...]. A promoção da saúde lida com estilos de vida [...]. A promoção da saúde trabalha a mobilização comunitária [...]. A promoção da saúde busca construir espaços saudáveis" (D1, p. 12-3). Outro efeito dessa composição de frases é tomar a promoção da saúde como sujeito, protagonista das ações. Já no D3 há uma preocupação de associar a promoção da saúde com os diversos aspectos do SUS, seja com o movimento sanitário, com a Vigilância em Saúde, ou com outros setores governamentais e sociais, com modalidades de formulação que acentuam um processo a desenvolver: "Entende-se que a promoção da saúde apresenta-se como um mecanismo de fortalecimento e implantação de uma política transversal, integrada e intersetorial" (D3, p. 13). Além disso, evita-se colocar a promoção na condição de sujeito das ações, mas na medida em que ela está submetida à noção maior de produção da saúde, sendo seu protagonismo coletivo, incluindo "a participação ativa de todos os sujeitos envolvidos em sua produção - usuários, movimentos sociais, trabalhadores da saúde, gestores do setor sanitário e de outros setores - na análise e na formulação de ações que visem à melhoria da qualidade de vida" (D3, p. 9).

\section{A PNPS em foco}

A PNPS (D4) possui similaridades em relação ao documento de 2005. A seção Marco Teórico do D3 é praticamente reproduzida na Introdução do D4, havendo poucas modificações, nenhuma de destaque. Esse é o texto base elaborado na Secretaria Executiva do Ministério da Saúde, e um gestor lembra que o longo processo de discussão interna da PNPS produziu uma ampla revisão em todos os tópicos da mesma, menos nessa Introdução. As seções Estratégias de Implementação e Responsabilidades das Esferas de Gestão são completamente inéditas.

Retomando a perspectiva da dimensão tridimensional do discurso, na análise do texto em si destaca-se a falta de coesão entre a discussão conceitual desenvolvida, especialmente na Introdução e na seção Ações Específicas. Se a direção almejada é não ter por foco a mudança de estilos de vida, as ações priorizadas caminham majoritariamente nesta direção. Das sete ações, apenas as duas últimas não têm por centro a mudança de hábitos de vida, de cunho mais preventivo do que promocional. E curiosamente, se o grupo redator, ainda na Secretaria Executiva do Ministério da Saúde, optou por substituir a expressão "estilos de vida" por "modos de viver" a fim de salientar a dependência do viver de determinações mais amplas do que a escolha individual, a expressão proscrita retorna em duas ocasiões na última seção. Mesmo que dos dez nomes que assinam a PNPS metade tenha participado da redação do D3. Um dos gestores presente desde o início das discussões na Secretaria Executiva do Ministério da Saúde traz uma avaliação esclarecedora, o que nos conduz à dimensão da análise da prática social: "O único financiamento que tinha era para isso, não era para outra coisa. Você tem dinheiro para quê? Para o combate ao cigarro. Você pode até querer diferente, mas o dinheiro que a OMS e OPAS passaram, que o Ministério liberou, vem com foco... então esse documento é um híbrido de vários contextos, situações".

Essa avaliação pode valer para outras políticas. A construção de políticas públicas lida com situações híbridas e por isto há sempre uma di- 
mensão paradoxal na elaboração das mesmas. Segundo Stone 20, essa dimensão paradoxal não é acidental, mas um componente inerente das políticas públicas, pois tanto seus conceitos quanto seus instrumentos são sempre resultantes de luta política. Vale destacar a forte determinação ocasionada pelos procedimentos de indução e financiamento por parte dos organismos internacionais. Evidentemente isso não é um mal em si mesmo. Ao contrário, somente após essa indução a promoção saiu dos textos legais e incorporou-se, mesmo que incipientemente, às práticas de assistência em nosso país. O modelo de atenção com foco na doença possui uma força historicamente estabelecida, que não cede apenas por boas intenções. Decisões governamentais precisam ser tomadas e implementadas com financiamento. Esse foi um dos méritos da PNPS. A maioria dos entrevistados salientou o avanço que significou termos atualmente mais de 1.500 municípios com financiamento da PNPS.

Ao analisarmos a prática discursiva da PNPS, temos um gênero de texto governamental. Como é próprio desse gênero, em sua intertextualidade há uma predominância de referências a outros textos de governo. Das sete, temos cinco referências a textos governamentais e as outras duas são à Constituição e à $8 \underline{\text { a }}$ CNS. Um dos gestores afirma que houve certo patrulhamento para evitar referências explícitas a autores específicos, mesmo que suas ideias estivessem presentes na Introdução.

Os "produtores" do texto são majoritariamente oriundos do governo, incluindo, além disso, alguns representantes de centros de pesquisas e um representante da ANS. Apesar da presença desse último, a PNPS não contempla uma discussão da saúde privada/suplementar. Há vários anos, Kickbusch 21 tem discutido sobre as consequências do "encontro" entre a saúde pública e a chamada "indústria da saúde", que utiliza elementos do discurso da promoção da saúde para fortalecer sua própria expansão. A indústria da saúde busca ampliar seus serviços, ancorada, entre outras coisas, no discurso promocional da saúde pública, mas mantendo a lógica da saúde como mercadoria, própria do setor privado. Mesmo assim, a opção do Ministério da Saúde foi por uma PNPS predominantemente voltada para o setor público. Isso se expressa quando localizamos seus "consumidores" preferenciais, a quem é dedicada toda a seção Responsabilidades: os gestores federais, estaduais e municipais. Apenas secundariamente, percebe-se nas Ações Específicas que se visa a atingir o conjunto da sociedade brasileira. A relação entre produtores e consumidores do discurso da Política estabelece seu escopo voltado para o setor público-governamental.
Temos uma PNPS escrita por várias mãos e por vários grupos, tendo acontecido ao menos duas grandes rodadas de discussões, uma sob a condução da Secretaria Executiva e outra conduzida pela Secretaria de Vigilância em Saúde do Ministério da Saúde. O CONASEM foi referido por um gestor e um pesquisador. Ambos acentuaram a qualidade das contribuições oriundas do representante dos secretários municipais. As menções aos debates ocorridos na Comissão Intergestores Tripartite são abundantes nas entrevistas. A atuação do Comitê Gestor da Política, tipo de formação inédita no Ministério da Saúde, que permanece com sua rotina de reuniões mensais para acompanhamento da implementação da PNPS, também foi destacada pelos entrevistados. Esse Comitê tem atualmente a tarefa de efetuar uma revisão da PNPS, especialmente trazendo maior ênfase aos determinantes sociais e atualizando a agenda de prioridades.

Finalmente, há que se reconhecer a importância histórica da formulação dessa PNPS no que tange aos avanços na realização plena do SUS. Isso é enunciado por um dos gestores: "Algo que estava só no texto constitucional de 88, só vira uma política em 2006, e assim ficamos até então com a declaração de intenções, mas sem operacionalizar a política".

\section{Conclusão}

Se classificarmos as fases do ciclo da política por definição de agenda, formulação, implementação e avaliação, esta pesquisa se voltou para as duas primeiras. Por essa razão os aspectos, não menos importantes, ligados à sua implementação não foram abordados, mas merecem investigação específica. No que tange às duas fases estudadas, sobressai a força dos organismos internacionais tanto na definição da agenda quanto na forma final do texto, especialmente nas Ações Específicas, fortalecendo sua dimensão preventivista. Isso não difere de países com maior trajetória nesse debate, como o Canadá, onde a promoção da saúde ainda permanece fortemente ancorada num paradigma centrado na patologia, com programas desenvolvidos com base no modelo epidemiológico de fatores de risco 22. A indução, via financiamento do PNUD, configurou-se num determinante crucial para a institucionalização da PNPS, conforme indica a literatura 2,3, e foi confirmada pelos entrevistados. Um dos gestores, como visto anteriormente, reconheceu que os recursos oriundos da OMS e OPAS impuseram a direção dos investimentos e das ações. Além disso, a "estratégia global para alimentação, atividade física e saúde" da OMS 
contribuiu decisivamente para as definições das ações da PNPS (D3) 4. Visto dessa perspectiva, a polarização entre movimento sanitário versus movimento internacional de promoção da saúde é um falso problema. O que é relevante não é ressaltar uma oposição excludente, mas garantir uma apropriação da discussão e do apoio internacional que seja condizente com a nossa realidade histórica e institucional.

Outro elemento que merece destaque é o processo de produção negociada de consenso, árduo, mas vital, que a atual estrutura do Ministério da Saúde exige para a formulação de políticas e programas, e que a PNPS viveu intensamente e mesmo inovou mediante a criação do Comitê
Gestor, em função do entendimento que essa política precisava ser pensada de modo transversal ao conjunto da saúde e não localizada em um subsetor específico. Temos assim um movimento importante tanto do ponto de vista de formulação de políticas quanto de processos de gestão no Ministério da Saúde. Como lembra um pesquisador entrevistado: "A avaliação do governo de transição era que havia uma fragmentação da máquina, que era incompatível com o projeto do sistema único". Nesse aspecto, com seu processo de construção transversal e dialógico, a PNPS representou um avanço importante na elaboração de políticas de saúde.

\section{Resumen}

Se investigaron los procesos de creación de la Política Nacional de Promoción de la Salud (PNPS), a través del análisis de tres documentos producidos por el Ministerio de Salud entre los años 2002 y 2005 y del texto final de la PNPS. Se entrevistó a cinco personas que participaron en la creación de la PNPS, de las cuales tres eran gestores del Ministerio de Salud y dos investigadores. Los documentos se analizaron mediante el método de análisis del discurso. El artículo contribuye a la profundización de los debates sobre el proceso de construcción de la PNPS. La promoción de la salud reveló sus antagonismos, lo que motivó el retraso en su aprobación final. El estímulo internacional a través de la financiación demostró que era un elemento crucial para la definición de la forma final de la política, provocándose el retorno al criticado énfasis en el cambio de estilo de vida en sus "acciones". Se destaca el proceso de producción negociada de consenso, que culminó con la creación del comité gestor de la PNPS, con la participación de diversos subsectores, convirtiéndose en una estructura innovadora en el Ministerio de Salud.

Promoción de la Salud; Politica de Salud; Sistema Único de Salud; Publicaciones Gubernamentales

\section{Colaboradores}

J. L. Ferreira Neto contribuiu com todas as etapas de produção do artigo: concepção, análise e interpretação dos dados, redação, revisão crítica do conteúdo e aprovação final da versão a ser publicada. L. Kind, M. C. C. Resende e N. S. Colen contribuíram com a análise e interpretação dos dados, revisão crítica e aprovação final da versão a ser publicada.

\section{Agradecimentos}

Ao CNPq e à Fundação de Amparo à Pesquisa do Estado de Minas Gerais FAPEMIG, pelo apoio financeiro. 


\section{Referências}

1. Foucault M. A ordem do discurso. São Paulo: Loyola Editora; 1996.

2. Schlager E. A comparison of frameworks, theories, and models of policy processes. In: Sabatier P, editor. Theories of the policy process. 2nd Ed. Boulder: Westview Press; 2010. p. 292-319.

3. Castro A. A institucionalização da promoção da saúde no Sistema Único de Saúde. In: União Internacional de Promoção da Saúde e Educação para a saúde, Oficina Regional Latino-Americana, organizadores. Eqüidade, compromisso social e qualidade de vida. Boletim da Sub-região Brasil 2005; Ano VII(10). http://openlink.br.inter.net/vllima. orla/boletim10.pdf (acessado em 12/Out/2011).

4. Buss PM, Carvalho AI. Desenvolvimento da promoção da saúde no Brasil nos últimos vinte anos (1988-2008). Ciênc Saúde Coletiva 2009; 14:230516.

5. Malta D, Castro AM, Gosch CS, Cruz DKA, Bressan A, Nogueira JD, et al. A Política Nacional de Promoção da Saúde e a agenda da atividade física no contexto do SUS. Epidemiol Serv Saúde 2009; 18:79-86.

6. Castro A, Malo M. SUS: ressignificando a promoção da saúde. São Paulo: Editora Hucitec; 2006.

7. Lalonde M. A new perceptive on the health of Canadians: a working document. Ottawa: Ministry of Health and Welfare; 1981.

8. Carvalho SR. As contradições da promoção à saúde em relação à produção de sujeitos e à mudança social. Ciênc Saúde Coletiva 2004; 9:669-78.

9. Teixeira CF. Promoção da saúde e SUS: um diálogo pertinente. In: Castro A, Malo M, organizadores. SUS: ressignificando a promoção da saúde. São Paulo: Editora Hucitec; 2006. p. 41-61.

10. Ferreira Neto JL, Kind L. Promoção da saúde: práticas grupais na estratégia saúde da família. São Paulo: Editora Hucitec; 2011.

11. Paim JS. Vigilância da Saúde: tendências de reorientação de modelos assistenciais para a promoção da saúde. In: Czeresnia D, Freitas CM, organizadores. Promoção da saúde: conceitos, reflexões, tendências. Rio de Janeiro: Editora Fiocruz; 2003. p. 161-74.

12. Freitas CM. A vigilância da saúde para a promoção da saúde. In: Czeresnia D, Freitas CM, organizadores. Promoção da saúde: conceitos, reflexões, tendências. Rio de Janeiro: Editora Fiocruz; 2003. p. 140-59.
13. Sabatier P. Theories of the policy process. $2^{\text {nd }}$ Ed. Boulder: Westview Press; 2007.

14. Celard A. A análise documental. In: Poupart J, Deslauriers J-P, Groulx L-H, Laperrière A, Mayer R, Pires AP, organizadores. A pesquisa qualitativa: enfoques epistemológicos e metodológicos. 2a Ed. Petrópolis: Editora Vozes; 2010. p. 295-316.

15. Ministério da Saúde. Política Nacional de Promoção da Saúde (documento para discussão); 2002. http://dtr2001.saude.gov.br/editora/produ tos/livros/genero/s00b.htm (acessado em 12/Set/ 2010).

16. Fairclough N. Discurso e mudança social. Brasília: Editora UnB; 2001.

17. Rocha D. O movimento da promoção da Saúde na década e 1990: um estudo do seu desenvolvimento e difusão na saúde pública brasileira [Tese de Doutorado]. São Paulo: Faculdade de Saúde Pública, Universidade de São Paulo; 2001.

18. Campos GWS. Prefácio. In: Castro A, Malo M, organizadores. SUS: ressignificando a promoção da saúde. São Paulo: Editora Hucitec; 2006. p. 11-2.

19. Faria TW. Dilemas e consensos: a seguridade social brasileira na Assembléia Nacional Constituinte de 1987/1988 [Dissertação de Mestrado]. Rio de Janeiro: Instituto de Medicina Social, Universidade do Estado do Rio de Janeiro; 1997.

20. Stone D. Policy paradox: the art of political decision making. $3^{\text {rd }}$ Ed. New York: Norton \& Company; 2002.

21. Kickbusch I, Payne L. Twenty-first century health promotion: the public health revolution meets the wellness revolution. Health Promot Int 2003; 18:275-8.

22. O'Neill M, Pederson A, Dupéré S, Rootman I. Conclusion. In: O'Neill M, Pederson A, Dupéré S, Rootman I, editors. Health promotion in Canada: critical perspectives. 2nd Ed. Toronto: Canadian Scholars Press; 2007. p. 371-88.

Recebido em 09/Mar/2012

Versão final reapresentada em 11/Abr/2013

Aprovado em 08/Mai/2013 